\title{
UNA MIRADA DIDÁCTICA SOBRE EL TIEMPO Y EL ESPACIO REGIONAL. PENSAR SANTA CRUZ
}

\author{
A DIDACTIC VIEW ABOUT TIME AND REGIONAL SPACE. \\ THINKING ABOUT SANTA CRUZ
}

Vanessa Mazú*

Resumo: Se presentan aquí los lineamientos didácticos y disciplinares que orientaron una experiencia de cursos - taller, que desde la Cátedra de Didáctica de las Cs. Sociales ${ }^{1}$ buscó integrar en una actividad de Investigación y Extensión dos tipos de saberes que fluctúan en la enseñanza de lo social: los identificados como tradicionales vinculados con los nuevos conceptos y principios que guían el área, tanto en su desarrollo epistemológico, como en las prácticas educativas. Ésta se destinó a docentes del Nivel Primario, y durante los diferentes encuentros, se definieron conceptos básicos del área aplicados al estudio y enseñanza del ámbito histórico y geográfico regional, orientando la búsqueda de información y recursos y diseñando estrategias didácticas que permitieran el abordaje escolar de la realidad provincial.

Palavras chave: Didáctica de lo Social; Contenidos Escolares; Historia Regional.

\begin{abstract}
This study presents the didactic and disciplinary guidelines of a course experience workshops, which since the discipline Didactics of the Social Sciences have sought to integrate, in a research and extension activity, the two types of knowledge that fluctuate in the social teaching: those identified as traditional and those linked to the new concepts and principles that guide the area, both in the epistemological development and in the educational practices. It was designed for teachers of primary level education, and through the meetings it was defined the basic concepts of the area that are applied to the study and teaching of historical and regional geography, providing guidance to the search for information and resource as well as establishing didactic strategies that allowed a school approach to the provincial reality.
\end{abstract}

Keywords: Didactics of the Social; School Contents; Regional History. 
Se comparten aquí los lineamientos didácticos y disciplinares que guiaron una experiencia, la cual bajo la dinámica de cursos - taller, en torno a la Didáctica de las Cs. Sociales buscó integrar en una actividad de Investigación / Extensión, dos tipos de saberes que fluctúan en la enseñanza de lo social: los identificados como tradicionales, vinculados con los nuevos conceptos y principios que guían el área, tanto en su desarrollo epistemológico, como en las prácticas educativas.

La misma se destinó a docentes del Nivel Primario $^{2}$, y tuvo su origen en un trabajo colaborativo sostenido durante dos años, en el que los mismos planteaban la falta de materiales didácticos y de orientaciones para la enseñanza de la historia regional. Durante los diferentes encuentros se definieron conceptos básicos del área aplicados al estudio y enseñanza del ámbito histórico y geográfico regional, orientando la búsqueda de información y recursos y diseñando estrategias didácticas que permitieran el abordaje escolar de la realidad provincial, siendo el marco teórico referencial el producido en la actividad de investigación, cuyos resultados fueron publicados en eventos científicos.

El planteo central de los maestros era cómo enseñar "la Provincia", ya que la mayoría no son oriundos de la región, siendo reflejo del proceso migratorio constante y en particular, porque la configuración histórica de Santa Cruz no se condice plenamente con la periodización y territorialización que habitualmente se enseña sobre "lo nacional". Para atender a esta demanda, se propusieron tres bloques temáticos, vinculados con los ejes de organización de contenidos establecidos por los Diseños Curriculares: Santa Cruz como territorio, como espacio y como lugar; Su Gente y su Historia y La enseñanza de Santa Cruz en clave de identidad.

La experiencia se desarrolló durante tres encuentros, con docentes de todas las escuelas públicas de la localidad. En esta oportunidad presentamos los lineamientos didácticos y disciplinares que la orientaron.

Desde el punto de vista de la dinámica curricular, tanto en los Contenidos Básicos Comunes, como en los Diseños Curriculares y en los Núcleos de Aprendizaje Prioritario $^{3}$, se plantea que el acercamiento de los niños a la comprensión de la realidad social como fenómeno integral, debe hacerse en función de los criterios de significatividad, progresión espacial y complejidad creciente.

Así, en los primeros años de escolaridad, los conceptos estructurantes del área se ordenan en una secuencia que va desde lo individual - familiar, a lo institucional - local, para luego trascender, en los ciclos siguientes a los espacios provincial, regional, nacional y continental, variando también los tópicos de abordaje: vida cotidiana, cambios y permanencias a través del tiempo, modos de organización social del trabajo, conflictos sociales, etc.
En este proceso se sitúa la necesidad de contar con herramientas que permitan dar cuenta de esa tarea en relación a la Provincia, recorte espacial habitualmente propuesto para el 4to. Año de la Educación Primaria.

Por otra parte, en la Escuela hoy transita un proceso de resignificación de los contenidos escolares totalmente nuevo, al incorporarse problemáticas que transversalizan la enseñanza y que no estuvieron presentes en la formación inicial de maestros hasta hace relativamente poco. Por ejemplo, los Pueblos Originarios como eje problematizador y los géneros desafían la enseñanza convencional, demandando la visibilización de amplios sectores sociales, tradicionalmente considerados como subalternos. En igual sentido, la educación ambiental exige una visión integral de las Ciencias Sociales, que tal como sucede con la enseñanza de la denominada "historia reciente", pone en tensión directa la subjetividad individual con los discursos colectivos. Y esto es tal vez el mayor reto: incluir estas temáticas como perspectivas, no como saberes separados.

\section{Ejes y temas}

La propuesta se desarrolló en base a tres bloques temáticos que en la dinámica escolar pueden ser abordados en cualquier orden; cada uno se centró en una dimensión de la realidad provincial; se enunciaron los Ejes de Contenidos del Diseño Curricular Provincial en que se encuadran, las expectativas de logro de la Unidad Pedagógica y la dimensión conceptual con que se relacionan directamente los temas. Tras una presentación general, se definieron algunos conceptos básicos, orientando luego la búsqueda de información y recursos, a la vez que se sugirieron estrategias didácticas para su abordaje.

\section{El Espacio: Santa Cruz como territorio, como espacio y como lugar.}

Este eje se trabajó a partir de tres temas: a) Localización y gráfica del espacio; b) Revisión de conceptos geográficos tradicionales: Estado, provincia, región, territorio; c) Los ambientes como escenario de los procesos sociales. Los puntos de partida en cada caso fueron los siguientes:

- La historia territorial del país contiene a Santa Cruz en una relación no lineal. Y el tiempo de las sociedades que hoy denominamos Argentina, no es uno. Una periodización de la organización del espacio refleja, ante todo, esa diversidad de intereses que entran en conflicto, las tensiones entre valoración de los recursos, posibilidades políticas y económicas y todo lo que conlleva el devenir histórico de una 
sociedad compleja y heterogénea.

- La explicación de los fenómenos sociales que resultan de las acciones tendientes a resolver las necesidades básicas requiere del conocimiento del ambiente. $\mathrm{Y}$ no es posible pensarlo sin las transformaciones que históricamente, los grupos imprimen en él. Esto explica el rol dado a la Geografía en la conformación de los Estados - Nación, y esencialmente, a través de los sistemas educativos. Las identidades colectivas, también se definen en un particular vínculo con el medio y la forma de nombrar el espacio como objeto de estudio y enseñanza no obedece a cuestiones naturales.

- Santa Cruz es, ante todo, un espacio organizado, un territorio con historia, conformado por paisajes diversos, reflejo de ambientes ricos en recursos, testimonio de la relación conflictiva que lo vincula en tanto "parte" de una organización más amplia. Enseñar sobre este espacio dinámico requiere poder definir estos aspectos de una misma unidad.

- En la visión del espacio como una totalidad construida, tanto en su dimensión tangible, como en el plano de la percepción - el espacio vivido - , se impone el análisis social de los elementos naturales a partir de conceptos o principios que lo explican, que lo hacen comprensible. Este reconocimiento del medio supone la posibilidad de identificar los recursos naturales que adquieren valor como recursos económicos, en cada tiempo y lugar.

Un ejemplo de las secuencias de conceptualización trabajadas es el siguiente:

El recurso natural entendido como ese atributo de la naturaleza que es potencialmente visto como central en el desarrollo de una actividad económica, que se inserta en un circuito productivo, generando y vinculando una red de relaciones entre distintos espacios.

Recursos también, cuya localización es en ambientes particulares, define formas de organización específicas: la fruticultura (por ejemplo desarrollada en la región de Los Antiguos), da un patrón de uso del suelo rural, distinto del que promueve la ganadería extensiva en la estepa.

El recurso (SUELO, en un caso, PASTURA en otro) habilita el desarrollo de actividades económicas que requieren distintos tipos de inversión en infraestructura, la producción es destinada a mercados diferentes; la vinculación con otras etapas productivas en otras regiones varía, y la organización social del trabajo prefigura actores sociales distintos. Este ejemplo nos muestra en la misma provincia dos formas de organización del espacio rural.

De igual modo, los espacios urbanos se definen por la localización estratégica en esos circuitos de distribución, la preminencia de qué función tienen en ese esquema y la propia historia que trazan en el conjunto provincial: pensemos en Puerto Deseado, en
Río Gallegos y en Río Turbio. La Primera, además de la actividad pesquera, es un puerto activo, abierto a la importación y que desde la denominada época colonial, posee un valor estratégico por las condiciones de puerto natural. Río Gallegos, cabecera administrativa del territorio, se sitúa en el centro de la actividad ovino ganadera, orientada a la producción lanar para mercado interno y de carne para exportación. Finalmente, Río Turbio - y por proyección su vecina 28 de Noviembre, ambas localidades fundadas en la década de 1940 -, emplazadas en torno al yacimiento de carbón, han cumplido también la condición de bastiones de frontera, en una región en la que geopolíticamente, la presencia del Estado se hace fundamental.

En este último sentido, podemos pensar que El Chaltén, ícono del pueblo Tehuelche, hoy centro turístico de renombre mundial, se vio potenciado cuando en la década de los 90, el conflicto con Chile por los Hielos Continentales, planteó al Estado la necesidad de sentar bandera como reafirmación de la soberanía.

Con esto queremos dar cuenta, que tampoco el entramado urbano es un proceso lineal, sino que esencialmente resulta de las condiciones que social, política y económicamente, definen los grupos en pugna, en una sociedad determinada.

\section{Santa Cruz: Su Gente, su Historia}

Para este tópico, los temas seleccionados fueron los siguientes: a) Poblamiento: pueblos, actores $\mathbf{y}$ actrices en el tiempo; b) pensar la Historia Provincial en el contexto Nacional y c) Las ciudades de la provincia: su localización en el espacio y el tiempo como testimonio.

El desarrollo de los mismos fue en torno a las siguientes ideas, que articulan tanto la complejidad del tiempo histórico como los grupos sociales que le confieren su particular dinamismo.

- La Dimensión histórica de un territorio tiende a ser siempre presentada en una cronología que se adapta o contiene criterios que aglutinan realidades distintas. Esas periodizaciones se establecen, generalmente, desde una posición de poder. En la historiografía nacional argentina, aún en sus variantes críticas, se reconocen cuatro grandes etapas: la era indígena, la era colonial, la era criolla y la era aluvial, definidas a partir de la combinación de las formas de organización económica, política y social ${ }^{4}$.

- Esta visión no deja de ser centralista, pero en la lógica que enunciábamos anteriormente, la localización en el tiempo también requiere de ese referenciamiento ante otro, más aún cuando ese otro en la actualidad nos contiene. 
- En síntesis, la historia de las provincias no se condice plenamente con la periodización de la historia nacional, o al menos, no en un sentido de linealidad.

- Respecto a la "era indígena", podemos decir que ésta tiene sus márgenes entre el poblamiento y el contacto con los europeos en el proceso de dominación colonial. Sin embargo, de considerar esto, ésta etapa en nuestra región debiera extenderse hasta la incorporación del territorio patagónico al Estado Nación, proceso conflictivo y polémico que se consuma hacia 1880, luego de la denominada Campaña del Desierto y no ya por el poder imperial sino por el estado nacional. Este proceso también subsume la era criolla, ya que aquí no se participa del proceso de conformación de ese estado, si no que el estado es la imposición que consuma la derrota.

¿Entra entonces Santa Cruz en la Historia recién en la era aluvial? En cierto modo, la integración institucionalizada sí. No obstante, hubo siempre historia en estas tierras. El interrogante es ¿cómo contarla?

Atendiendo los desarrollos históricos particulares, se propuso una periodización que contempla las siguientes etapas: poblamiento, época de las Exploraciones, conquista y territorialización, entendiendo en este último aspecto la incorporación progresiva y plena al dominio del Estado - Nación y la institucionalización como Provincia, como procesos paralelos a la fundación de ciudades, siendo que este último respondió antes a la lógica económico productiva que a la política. Al respecto, se tomó la siguiente idea como premisa de enlace para la cerrar la reflexión teórica y desde ella diseñar una estrategia didáctica:

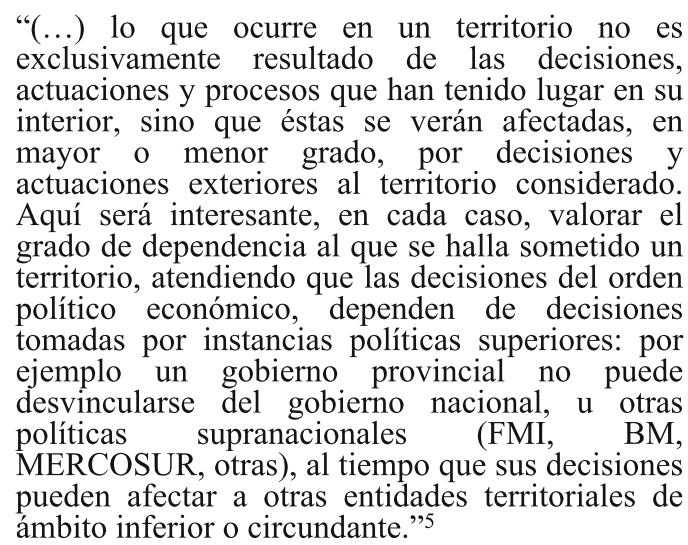

\section{La enseñanza de Santa Cruz en clave de identidad}

Finalmente, para el tercer eje, se propusieron los siguientes temas: a) La multiculturalidad como condición del presente: visibilización y diálogo; b) Las efemérides Provinciales, entre la fundación y la memoria: el estado, los pueblos, las fiestas, las luchas.
- El concepto de multiculturalidad supone la co - existencia de distintas culturas, el reconocimiento de "otros", que comparten un escenario y se vinculan, actúan, e interactúan. Pero en procesos complejos como el de la definición identitaria de una sociedad activa que desde el presente, y como expresión colectiva, tensiona con proyectos de futuro, la memoria y la redefinición de los patrones de relación, esa idea puede y debe ponerse en discusión. Esta tensión expresa el debate entre el reconocimiento de derechos, que no siempre se fundan en los mismos conceptos culturales y jurídicos en el proceso de conformación de una nueva identidad, que aún reconociendo las particularidades de cada grupo, define a la sociedad en construcción como un fenómeno signado por la interculturalidad.

- Las efemérides son fechas institucionalizadas que permiten "la recordación de lo efímero", esto es, de algo que duró un momento, y que su señalamiento constante, incorpora en el proceso de memoria colectiva. Las escuelas son ámbitos privilegiados de este procedimiento cultural y vimos oportuno reconocer algunas categorías de clasificación, de aquellas fechas que jalonan nuestro trabajo cotidiano, presentando las siguientes categorías:

* Decimos que una efeméride responde al Estado, cuando remite a un acontecimiento de la historia político - institucional: fundación de ciudades, sanción de la Constitución provincial, día del Escudo Provincial

* El concepto de efeméride del "pueblo" nos hace pensar en acontecimientos que el orden estatal no reconoce inicialmente, y que no expresan institucionalizaciones, por ejemplo, las que remiten a Pueblos Originarios desde prácticas culturales específicas como puede ser el Año Nuevo Mapuche, o el inicio de la temporada de caza de guanacos para los Tehuelches.

* En igual sentido, una expresión cultural que marca a las comunidades actuales, y refleja la diversidad de tradiciones que conviven en cada una, son las fiestas patronales de los migrantes de distintos orígenes o de los "santos protectores" de las actividades económicas: Santa Bárbara, La Virgen del Milagro, la Virgen de Urcupiña.

* También son "del pueblo", las situaciones de lucha. Por caso, las Huelgas Obreras de la década del 20, el 14 de Junio en Río Turbio, el 12 de Abril para los Docentes, remitiendo en todos los casos a situaciones violentas, enmarcadas en contextos de conflicto social.

La enumeración podría seguir, pero llegados a ese punto, se impone aquí la necesidad, a nivel institucional del debate en torno a la cuestión ideológica de lo que elegimos recordar, esto es, el carácter selectivo del proceso de construcción de la memoria colectiva en tanto escenario de disputas ideológicas. 


\section{Los Recursos}

En diálogo con los docentes, pudo inferirse que el abordaje de la provincia produce instancias de tensión, poniendo de manifiesto un complejo entramado de sensaciones al trabajar contenidos de Ciencias Sociales y ciertas dificultades que conlleva su tratamiento.

En el conjunto de inquietudes, las que representan tal vez la mayor demanda son, por una parte el desconocimiento del tema y por otra, que el material bibliográfico específico y referente al estudio de Santa Cruz, es muy escaso o insuficiente. Si bien la posibilidad de contar con recursos que nos acerquen a su estudio no es realmente inaccesible, la percepción de los maestros no indica lo mismo.

Con antelación al primer taller, se procedió a un relevamiento en las bibliotecas sobre los materiales didácticos posibles de ser utilizados en el desarrollo de temas inherentes al estudio de la provincia. Se observó que si existen, éstos son pocos y no alcanzan a cumplir las expectativas de síntesis y actualización que se espera caractericen la enseñanza. Circulan sólo dos manuales de texto, que cuentan con errores conceptuales e información errónea, que generan más tensión y confusión en el docente. ${ }^{6}$

Esto se complementa con algunos libros de literatura local - anecdotarios, poesía, historias de las comunidades- que si bien pueden tomarse como testimonios o fuentes para la historia local, no compensan el vacío informativo en que se sitúan los maestros.

En la experiencia aquí compartida, se parte de la idea que es mucha la información existente y que su dispersión - propia de que la misma se origine en distintas fuentes- hace difícil establecer criterios de selección que abarquen, si no la totalidad de aspectos y miradas sobre esta realidad, al menos un abanico amplio de lecturas sobre la misma.

Ante esta realidad y en el objetivo de propiciar otros mecanismos de búsqueda, relevamiento y posibles estrategias didácticas al incluir otras alternativas de conocimiento social como es el uso de internet y las posibilidades de su aprovechamiento como recurso virtual, se acompañó el dictado de los Talleres con dos recursos producidos especialmente: un $\mathrm{CD}$ interactivo en el que se encuentra el texto (Fig. 1) en el que se desarrollan teóricamente los ejes anteriormente presentados, una selección bibliográfica referenciada el Diseño Curricular Provincial, leyes y normativas vinculadas al trabajo docente, bibliografía referente a las efemérides provinciales y fechas referenciales cada localidad, marcos teóricos y aportes bibliográficos sobre Geografía e Historia de la Provincia, materiales extras para pensar la Didáctica de las Ciencias Sociales y un index de direcciones digitales, que remiten a distintos portales, tanto educativos como de información general, oficiales y no. También cuenta con un banco de imágenes para ser considerado como repositorio de recursos visuales.

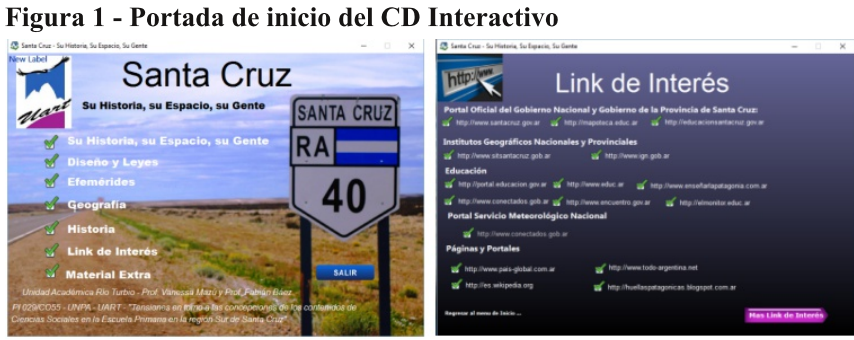

Fonte: Diseño y Producción de la cátedra

La selección de materiales presentada, conlleva un análisis de su aplicación e invita a navegar y enfrentarse al dilema de confirmar la veracidad de la amplitud de información que propone en el mundo virtual más allá del "Wikipedia" o de "Monografias.com", así como pone en discusión la idea de que la utilización de páginas oficiales de instituciones del Estado no implica tomar un lugar político, si no por el contrario es tomar el lugar real y concreto del docente, que debe tener postura crítica y reflexivamente utilizar este conocimiento para acercar a los alumnos a otro tipo de fuentes de información, en la búsqueda y la investigación en el mundo actual. Esto significa también repensar el uso de la información pública, toda vez que en los distintos portales sugeridos nos encontramos con un abanico de recursos (mapas, estadísticas, gráficos, textos y hasta propuestas para el aula), que suponen una puerta de entrada para convertir la clase de Ciencias Sociales en un espacio dinámico para el desarrollo de criterios en el manejo autónomo y crítico del conocimiento. Pongamos por caso el Portal Oficial del Gobierno de la Pcia. de Santa Cruz (Fig 2); desde el inicio de esta página pueden visitarse muchos sitios de los estamentos provinciales que poseen variada información estadística sobre población, datos relevante sobre las municipalidades, mapas virtuales, bibliografía sobre prevención y educación vial para trabajar desde la página, links que nos vinculan sobre la modalidad educación cultural bilingüe, entre otros.

Figura 2: Portales oficiales del Gobierno de la Pcia. De Santa Cruz ${ }^{7}$ 8

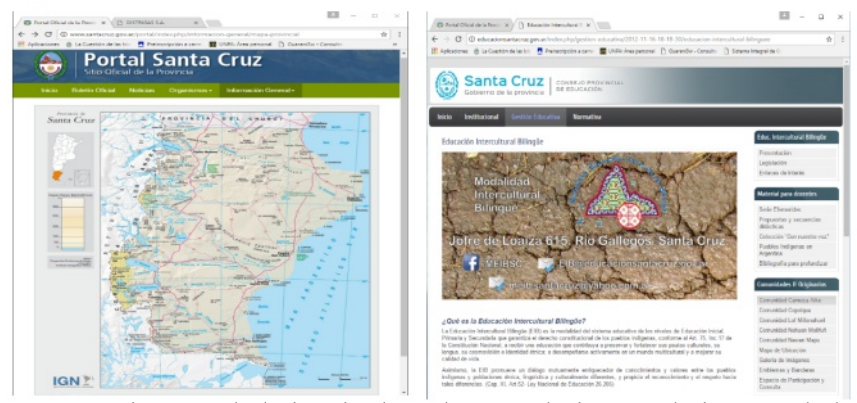

Fonte: La imagen de la izquierda es la nota al pie $n^{\circ} 8$, la imagen de la derecha es la no 9 .

\section{Hacia una didáctica con sentido: cómo enseñar la provincia}

Los elementos que hemos considerado hasta aquí para comprender los fenómenos históricos y ambientales en la Pcia. De Santa Cruz nos señalan la complejidad de intentar la lectura de estos, en marcos 
explicativos generales, a la vez que evidencian el apasionante desafío de descubrir y crear puentes de acercamiento a la realidad que nos ayuden a situarnos como sujetos partícipes de historias particulares. La escuela en eso tiene mucho por andar y en ella, los docentes, mucho por hacer. Reconocernos en el otro y con el otro, en actos sucesivos de reflexión colectiva posiciona a la enseñanza de lo social como una verdadera herramienta de transformación.

Acordando en la idea de que las elecciones pedagógicas son resultado de consensos que debemos alcanzar en una comunidad educativa específica, adecuada a nuestros grupos y consecuente con los fines que nos propongamos, compartimos aquí algunas conclusiones. Por una parte, es evidente que la multiplicidad de conocimientos no permite resolver la selección de problemas a enseñar por simple agregación, o suma de contenidos de las distintas ciencias.

En igual sentido, debe atenderse la relación sólida entre saberes populares y académicos. El conocimiento a enseñar debe ser "conforme" con el conocimiento científico, por lo que cabe tener en cuenta las exigencias de las disciplinas. Que un "saber popular esté presente en el aula, no le da rigurosidad ni fuerza de certeza, pero sí debe ser atendido en su justa influencia, por ejemplo, las tradiciones en los pueblos mineros, en las que las mujeres no ingresan a los espacios productivos, porque la "tierra se enoja"... enseñar el mito no debiera implicar su refuerzo.

Finalmente, dar a la secuenciación continuidad y progresión, de manera que el conocimiento se vaya construyendo, asegurando y ampliando supone integración y equilibrio entre los conocimientos, de manera que se integren progresivamente y que el interés por las Ciencias Sociales no se reduzca a priorizar unos pocos temas voluntariamente privilegiados por el docente.

Hasta aquí el primer acercamiento. Tal vez resulte incompleto, siempre será discutible, pero nos queda el entusiasmo de saber que este camino recién empieza, y que la dinámica de echar a andar, nos volverá a encontrar en la suma de nuevos debates y nuevos desafíos, convencidos sí, como dijo Cortázar, de que Cultura es el ejercicio profundo de la identidad. Muchas Gracias!.

\section{Bibliografía}

Consejo Provincial de Educación. Diseño Curricular de la Provincia de Santa Cruz para la Educación Primaria. 2015.

MAZÚ, V. y BÁEZ, S., Reflexiones en torno a las prácticas docentes en la enseñanza de lo social en el nivel primario. Disponible en:

encuentroespaciosenblanco.unicen.edu.ar/inicio.xhtml

Acceso: 19/02/2018.

\section{Notas}

1 Profesorado para la Educación Primaria - UNPA- UART Proyecto de Investigación 29/C065 UNPA - UART "Las Subjetividades de los docentes y la enseñanza de lo Social en la Escuela Primaria".

${ }^{2}$ En la localidad hay 4 escuelas primarias públicas; en cada una hay dos divisiones de 4to. Año, quienes tienen a su cargo la enseñanza de diversos temas vinculados a la enseñanza de la realidad provincial. Participaron un total de 30 docentes, convocados desde cada equipo directivo. El promedio por curso es de 25 niños.

${ }^{3}$ Los CBC, o Contenidos Básicos Comunes fueron establecidos en el año 1994, según Resolución Nº39/94 Del Consejo Federal de Educación y en el marco de la Ley Federal de Educación, como curriculum básico para todo el país. Los NAP o Núcleos de Aprendizaje Prioritario son Contenidos Comunes del Sistema educativo argentino, consensuados y establecidos por Acuerdo del CFCyE $\mathrm{N}^{\circ} 214 / 04$, a efectos de dar unidad al mismo, tendiendo a superar las desigualdades regionales y socioculturales.

4 En pág. 15 del Cap. de Ciencias Sociales del Diseño Curricular Provincial, se presenta la argumentación de cada una de estas etapas, atendiendo la propuesta que formulara desde 1970, el Historiador Argentino José Luis Romero, como una periodización específica de la historia nacional y que fue tomada desde la Reforma Educativa de los 90 como criterio en todas las currículas oficiales del país.

${ }^{5}$ Diseño Curricular Provincial : Cap. Cs. Sociales Pág.29

6 "Santa Cruz, Mi Provincia", de Marcelino Castro García, sin ningún dato editorial.

${ }^{7}$ Disponible en: http://www.santacruz.gov.ar/portal/

${ }^{8}$ Disponible en:

http://educacionsantacruz.gov.ar/index.php/gestioneducativa/2012-11-16-18-18-30/educacion-intercultural-bilinguee 